\title{
Egzoz Sistemi Soğuk Kısım Deplasman Hesabı
}

\author{
*1. Orhan Pehlivan ve ${ }^{2}$ Canberk Çıbık \\ *1,2TOFAŞ, Ar-Ge Direktörlüğü,Motor Transmisyon ve Kontrol Sistemleri Müdürlüğü, Bursa,Türkiye
}

\section{Özet :}

Egzoz sistemi esnek mafsal, egzos işleme parçaları, susturucular, elastik askı, askı destekleri ve borular içeren karmaşık bir sistemdir. Bu systemin NVH karakteristikleri hem parçaların dayanımları hem de müşteri memnuniyeti açısından önemlidir. Bu çalışma, egzos soğuk ucu yer değiştirmeleri ve çevre parçalara yakınlaşmayı elde etmek için yapılan büyük er değiştirme yarı static analizlerini içerir. İlk olarak, dizel motora sahip hafif bir ticari aracın egzos sistemi soğuk kısmının lineer olmayan statik analizi yapılmıştır. Bu analizde system, ALTAIR Hyperworks simülasyon araçlarında, motor yer değiştirmeleri ve ağırlık yüklerinin üst üste binmesi olarak çeşitli senaryolar ile tahrik edilmiştir. Sanal analizden sonra egzos sistemi soğuk taraf yer değiştirmeleri ve mekanik travers kolu ile esnek mafsal arasındaki yakınlık kaydedilmiştir. Bir sonraki adımda, en kritik senaryo çıkarılmış ve simülasyon ile gerçeklik arasındaki ilişkiyi kurmak adına testler yapılmıştır. Son olarak, sanal analiz ile test arasındaki korelasyon raporlanmıştır.

Anahtar kelimeler: Egzoz Sistemi, sonlu elemanlar metodu, yarı statik analiz, lineer olmayan analiz

\section{Calculation of Exhaust System Cold End Displacement}

Exhaust system is a complex sytem includes a variety of components and materials, such as flexible joint, aftertreatment parts, mufflers, elastic hangers, hanger brackets and pipes. NVH characteristics of the system is important in terms of material durability and customer satisfaction. This study includes large displacement, non-linear quasi-static analysis of the exhaust system cold end in order to obtain exhaust cold end displacements and proximity with the nearby components. Firstly, non-linear analysis of the the exhaust system cold end of a lightweight commercial vehicle with diesel engine was performed. In this analysis, system was excited via various scenarios as the superposition of engine displacements and gravitational loads on the simulation tools of ALTAIR Hyperworks. After the virtual analysis, exhaust system cold end displacements and the proximity between mechanical traverse and flexible joint was noted. In the next step, the most critical case was extracted, and the test was conducted in order to build the correlation between the simulation and reality. Finally, the correlation between the virtual analysis and test was reported.

Key words: Exhaust system, finite elements method, quasi-static analysis, nonlinear analysis

\section{Giriş}

Egzoz sistemi tasarımı, birçok sistemin etkileşiminin göz önünde bulundurulması gerekliliğinden ve bazı parametrelerin iyileştirilmesi bazılarını kötüleştirebileceğinden, karmaşık bir süreçtir. Sistemin optimizasyonu, termal ve akış sisteminin yanı sıra mekanik dayanım, titreşim, akustik gibi farklı disiplinlerin çalışılmasını da gerektirir.

$\mathrm{Bu}$ çalışmada, egzoz sisteminin soğuk kısmı olarak tanımlanan bölge, katalitik konvertörün

*Corresponding author: Address: TOFAŞ Türk Otomobil Fabrikası A.Ş., AR-GE Departmanı, İstanbul Cad., No:574, Osmangazi, Bursa, TURKEY. E-mail address: orhan.pehlivan @ tofas.com.tr, Phone: +902242610350 
çıkışından başlayıp egzoz gazlarının araçtan atmosfere atıldığı noktaya kadar uzanır. Mevcut çalışılan araçta egzoz soğuk kısmı esnek mafsal, monolit katalizör, egzoz askı plastikleri ve braketleri, flanşlar, kelepçeler ve borulardan oluşur ve bu sistem araca taban altından askı braketleri aracılığılyla monte edilir.

Egzoz sistemi temelde motor yükleri ve yol durumu yükleri olmak üzere iki yüke maruz kalır [1]. Bu iki farklı yükün ayrıştırılması, sistemin mekanik dayanımı açısından son derece önemlidir. Egzoz sistemi ve motor arasında bulunan esnek mafsalın temel görevi bu yükleri ayırarak iki sistemin hareketlerini birbirlerine aktarmadan absorbe etmektir [2].

Egzoz sisteminin büyük deplasmanlarının çalışılmasındaki başlıca sebep çevre parçalara olan yakınlaşmaları görmek ve kritik bir yakınlaşma veya temas olması durumunda buna çözüm getirmek için gerekli önlemleri almaktır. Bu deplasmanlar ve yakınlaşmalar, motor yükünden veya yol durumu yükünden kaynaklanabileceğinden, iki yükün eş zamanlı olarak uygulanması gerekir.

\section{Sistemin Sonlu Elemanlar Modeli}

Önceden belirtilen egzoz soğuk kısmın sonlu elemanlar modeli, borular ve flanşlar dışındaki önemli kısımlar adlandırılarak Şekil 1' de gösterilmiştir.

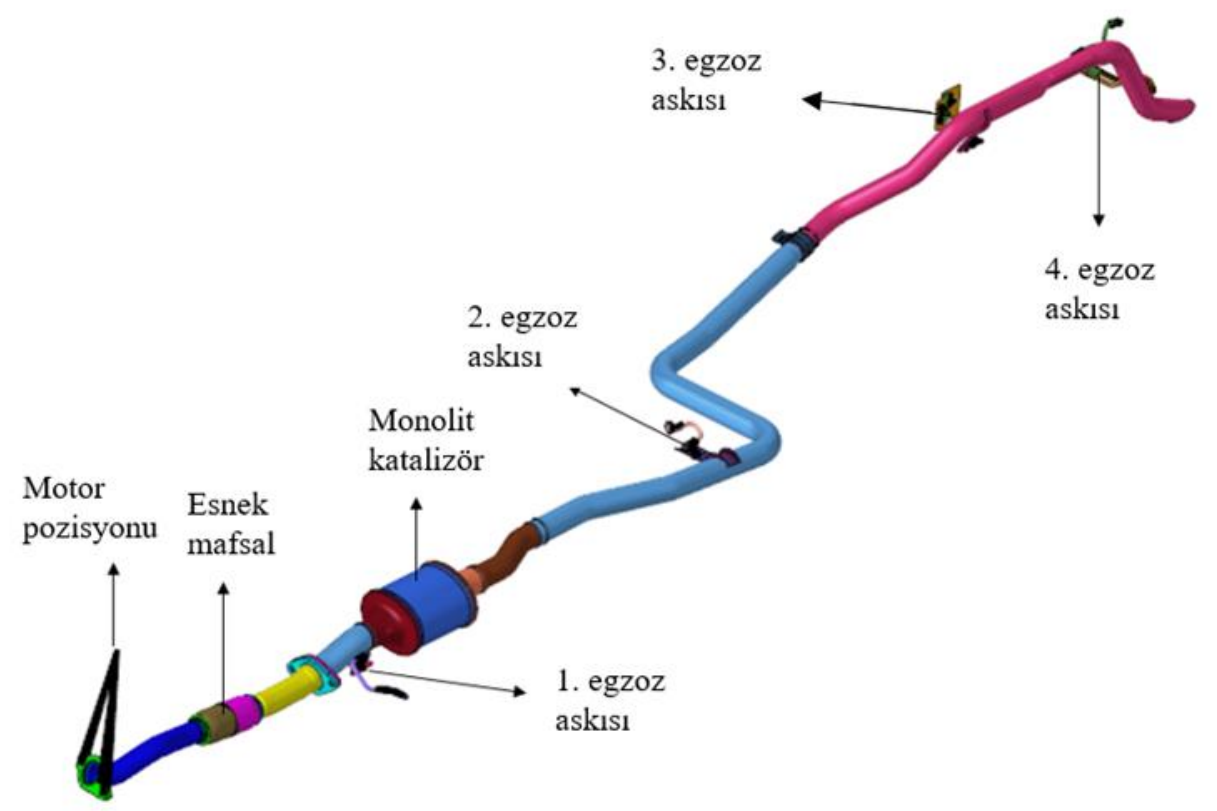

Şekil 1: Egzoz soğuk kısım sonlu elemanlar modeli

Sonlu elemanlar modelinde 2D kabuk ve 3D katı elemanlar kullanılmıştır. Çoğunlukla 2D kabuk elemanların kullanıldığı modelde, 3D katı eleman bulunan kısımlar kaynak bölgeleri, bazı ask1 braketleri, flanşlar ve monolit katalizör iç kısım olarak sınırlanmıştır. Monolit katalizörün içi 
petekli ve çok detaylı bir yapı olduğundan bu kısmın gerçekte olduğu gibi modellenmesi zordur ve modellenmesi halinde ise sistemin genel hareketi açısında bir etkisi olmayacağından bu kısım gerçekteki ağırlığına eşit olacak bir malzeme yoğunluğu kullanılarak tamamen içi dolu şekilde modellenmiştir.

Genel olarak sistemde çoğunlukla eleman boyutu $3 \mathrm{~mm}$ olarak kullanılmıştır. Boru-flanş, boruboru, flanş-flanş, motor-flanş, askı braketleri- gövde, elastik ask1-braket, esnek mafsal-boru gibi bağlantılarda 'rbe2' olarak adlandırılan rijit elemanlar kullanılmıştır. Şekil 2'de sistemin ilk ask1 bölgesi mesh yapısı detaylı olarak gösterilmiştir.

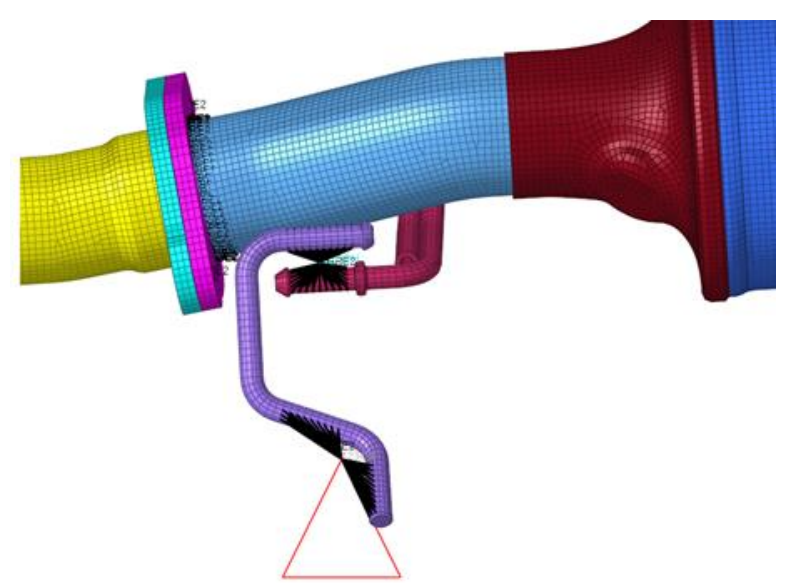

Şekil 2: İlk askı bölgesi detaylı gösterim

Egzoz sisteminde bölgesel sıcaklıklar, korozyon ihtimali ve mekanik dayanım göz önünde bulundurularak farklı malzemeler kullanılmaktadır. Egzoz sistemi soğuk kısımda kullanılan malzemeler Tablo 1'de gösterilmiştir.

Tablo 1: Malzeme özellikleri

\begin{tabular}{|c|c|c|c|}
\hline Malzeme & $\begin{array}{c}\text { Yoğunluk } \\
{[\mathbf{k g} / \mathbf{m 3}]}\end{array}$ & Poisson Oranı & $\begin{array}{c}\text { Young Modulü } \\
\text { [GPa] }\end{array}$ \\
\hline AISI 409 & 7700 & 0.28 & 215 \\
\hline AISI 441-439 & 7700 & 0.28 & 220 \\
\hline ER308L & 7850 & 0.28 & 200 \\
\hline FE510D & 7800 & 0.3 & 200 \\
\hline
\end{tabular}




\subsection{Esnek mafsal ve elastik askıların modellenmesi}

Egzoz sisteminde oluşacak olan hareketlerin ve titreşimlerin absorbe edilmesinde kullanılan esnek mafsal ve elastik askıların modellenmesinde 1D 'cbush' olarak adlandırılan, 3 eksen öteleme ve 3 eksen dönme olmak üzere direngenlik atanabilen yay elemanlar kullanılmıştır. Bu parçaların statik ve dinamik test sonuçlarında oluşturulan direngenlik eğrileri programa girilerek elastik askıların ve esnek mafsalın modellenmesi gerçekleştirilmiştir. Şekil 3'de esnek mafsalın sonlu elemanlar modeli gösterilmiştir.

Esnek mafsal direngenlik değeri statik test sonucuna dayanarak sabit olarak alınmıştır, çünkü, esnek mafsal, görece yüksek deplasman değerlerinde de sabit direngenlik sağlayabilmektedir.

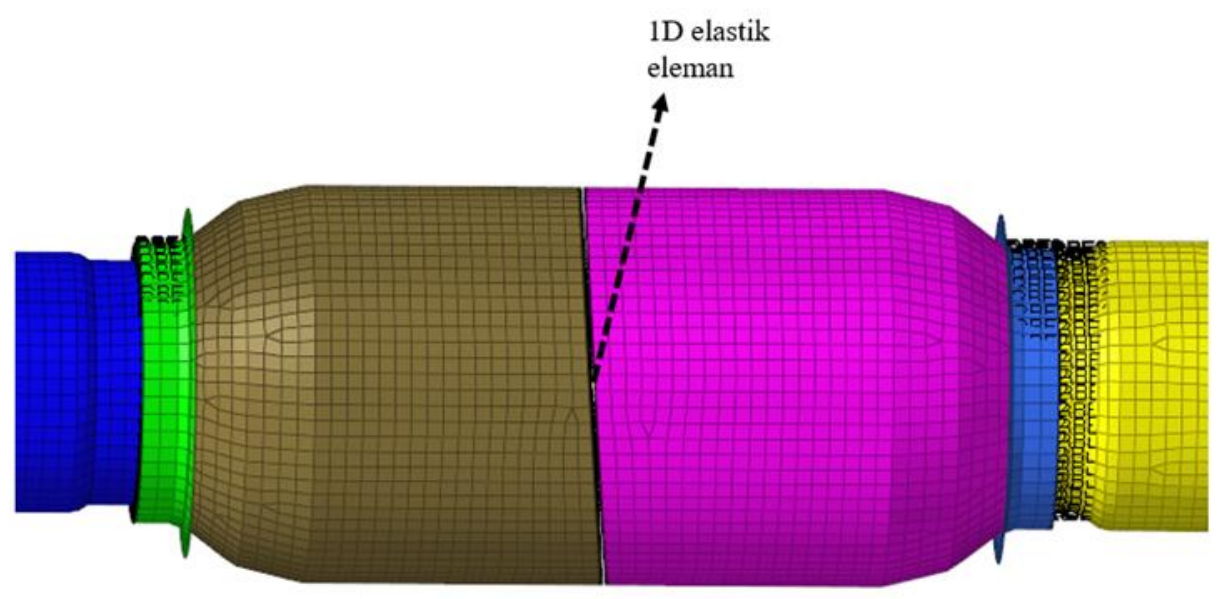

Şekil 3: Esnek mafsal modeli

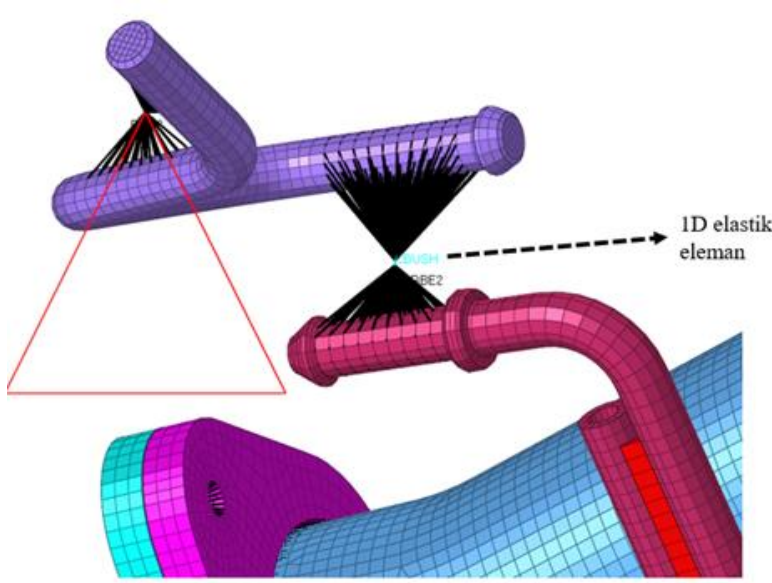

Şekil 4: 1 . Elastik askı modeli 
Şekil 5'te 1. elastik askının 3D görseli paylaşılmıştır.

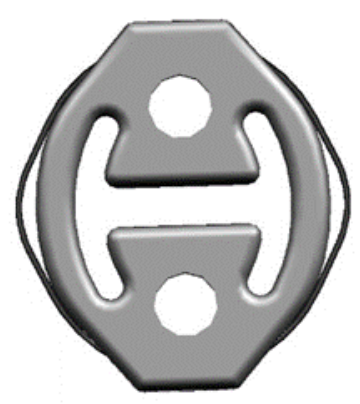

Şekil 5: 1. Elastik ask1

Örnek olması açısından Şekil 6'da 1. elastik askının statik çekme ve basma kuvvet-yer değiştirme test eğrisi gösterilmiştir. Egzoz soğuk kısım hareketlerinin incelenmesinde en kötü senaryo yaklaşımı göz önünde bulundurulduğundan, elastik askıların eğrileri girilirken nominal değerler yerine direngenliğin en düşük olduğu eğriler izlenmiş̧tir. Şekil 6 üzerinde bu kısımlar kırmızı ile gösterilmiştir. Bu sayede egzoz soğuk kısmın maksimum hareketi gözlemlenebilecektir.

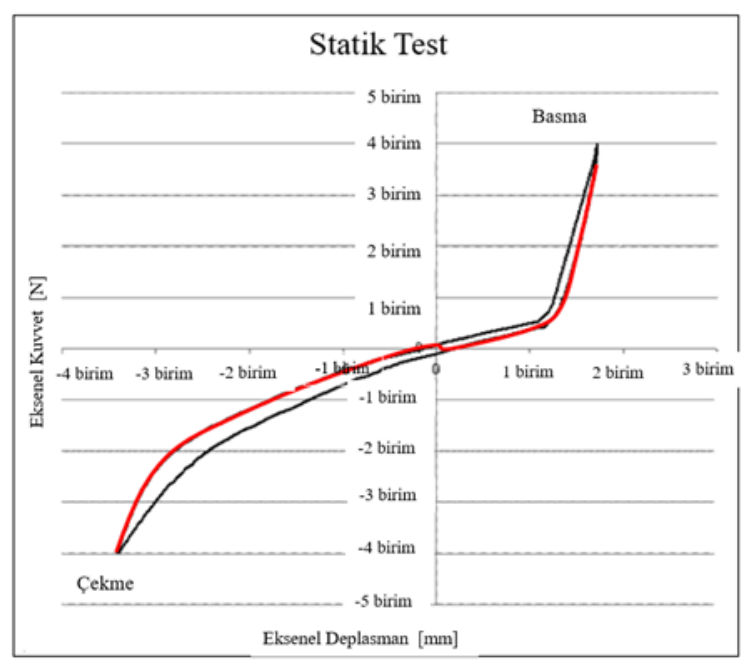

Şekil 6: 1. Elastik ask1 statik test kuvvet-yer değiştirme eğrisi

Lineer olmayan yarı-statik analiz metodolojisi ile egzoz soğuk kısmın büyük yer değiştirmeleri inceleneceğinden, düşük deplasmanlarda kullanılan sabit direngenlik ile statik davranışın dışına çıkılması gerekmektedir. Bu sebepten ötürü, Şekil 6'da gösterildiği gibi bir eğri girilerek, artan deplasmanlarda değişkenlik gösteren direngenlik değerleri adapte edilmiş̧ir.

\subsection{Yük ve analiz koşullart}

Önceden de bahsedildiği gibi, egzoz sistemi temelde iki farklı yük olan motor yükleri ve ağırlık yüklerine eş zamanlı olarak maruz kalmaktadır. Egzoz sisteminin hareketin doğru incelenebilmesi 
için, sonlu elemanlar modeli üzerinde bu iki kuvvet birlikte olarak uygulanmalıdır.

Tablo 2'de yük senaryoları tanımları gösterilmiştir. Her bir yük senaryosu motor yer değiştirme ve rotasyonları ile beraber araç yer çekimsel yükleri de içermektedir. Bu yük koşulları içerisinden, maksimum yol ve maksimum motor yükleri olarak problem yaratabileceği öngörülen bazı senaryolar seçilmiş ve uygulanmıştır.

Tablo 2: Yük senaryoları

\begin{tabular}{|l|}
\hline Yük Senaryolari Tanimlari \\
\hline Dikey ivmelenme \\
\hline Dikey ivmelenme negatif \\
\hline Ani frenleme \\
\hline Birinci vites normal kalkış \\
\hline Yatay ivmelenme \\
\hline Yatay ivmelenme geri \\
\hline Birinci vites debriyaj sınırında kalkış \\
\hline Dikey ve yatay tümsek \\
\hline Dikey ve yatay tümsek geri tepme \\
\hline Dikey ve yatay tümsek geri \\
\hline Dikey ve yatay tümsek ters geri tepme \\
\hline
\end{tabular}

Yol yükleri olarak, yer çekimsel yüklerin yer çekimi ivmesi ile çarpılmış değeri sisteme ağırlık yükü olarak uygulanmıştır. Motor yükleri olarak ise, motorun dinamik analizinden elde edilen, motor takozlarının sönümlemesi sonrasında oluşan yer değiştirme ve rotasyon miktarları, motorun ağırlık merkezinden uygulanmıştır.

Güç aktarım, yani, motor ve şanzıman kısmı egzoz hareketlerinde çok önemli bir rol oynamaktadır. Egzoz sistemi hareketinin doğru değerlendirilebilmesi için, güç aktarım kısmının modellenmesi gerekmektedir [3]. Motor ve şanzıman kütlesi ve ataleti, ağırlık merkezinden eklenerek motor takozlarına bağlanmalı ve motor tahrikinin egzoz üzerindeki etkisi incelenmelidir. Ancak bu çalışmada, motor yükü olarak verilen yer değiştirme ve rotasyonlar, motorun takozları ile birlikte dinamik analizi sonucu elde edilen ve motor üzerinden ölçülen değerler olduğundan, bu modelde güç aktarım kısımlarının eklenmesine ihtiyaç yoktur.

Egzoz soğuk kısmı, Tablo 2'de tanımlanan yükler altında büyük hareketler yapacaktır. Bundan dolayı, yarı-statik lineer olmayan analiz metodolojisi kullanılmışır. Egzoz soğuk kısmı başlangıçtan motor ağırlık merkezine, askı kısımlarından ise alt gövdeye bağlanacak şekilde rijit sinır koşulları uygulanmıştır.

\subsection{Analiz sonuçlart}

Analizler sonucunda, mekanik traverse ile esnek mafsal arasındaki mesafe her bir yük koşulu için not edilmiştir. Analiz sonuçları parametrik olarak Tablo 3’te gösterilmiştir. 
Tablo 3: Analiz sonuçları

\begin{tabular}{|l|l|l|}
\hline YÜK SENARYOLARI & $\begin{array}{l}\text { Mekanik travers kolu } \\
\text { ile esnek mafsal } \\
\text { arasındaki minimum } \\
\text { mesafe [mm] }\end{array}$ & $\begin{array}{l}\text { Farklı parçalar ile } \\
\text { yakınlaşma var ise } \\
\text { minimum mesafe } \\
\text { [mm] }\end{array}$ \\
\hline Dikey ivmelenme negatif & $37.2 \mathrm{a}$ & $25.6 \mathrm{a}$ (Travers üstü) \\
\hline Dikey ivmelenme & $53.2 \mathrm{a}$ & \\
\hline Ani frenleme & $45.0 \mathrm{a}$ & \\
\hline Birinci vites normal kalkış & $20.0 \mathrm{a}$ & \\
\hline Yatay ivmelenme & $48.2 \mathrm{a}$ & \\
\hline Yatay ivmelenme geri & $32.4 \mathrm{a}$ & \\
\hline Birinci vites patinaj sınırında kalkış & $14.5 \mathrm{a}$ & $20.2 \mathrm{a}$ (Travers üstü) \\
\hline Dikey ve yatay tümsek & $35.6 \mathrm{a}$ & \\
\hline Dikey ve yatay tümsek geri tepme & $54.0 \mathrm{a}$ & $24.6 \mathrm{a}$ (Travers üstü) \\
\hline Dikey ve yatay tümsek geri & $36.4 \mathrm{a}$ & \\
\hline Dikey ve yatay tümsek ters geri tepme & $48.8 \mathrm{a}$ & \\
\hline
\end{tabular}

Tablo 3'te görüldüğü gibi, sanal analizler sonucunda en kritik yük durumu olarak 'Birinci vites patinaj sınırında kalkış’ belirlenmiştir. En fazla yakınlaşmanın elde edildiği senaryodan yola çıkarak, kritik durumdaki dominant yükün motor yükü olduğu söylenebilir. Çalışmanın devamında bu senaryonun test edilmesine karar verilmiştir. Kritik senaryodaki yakınlaşma fiziksel olarak Şekil 7'de gösterilmiştir.

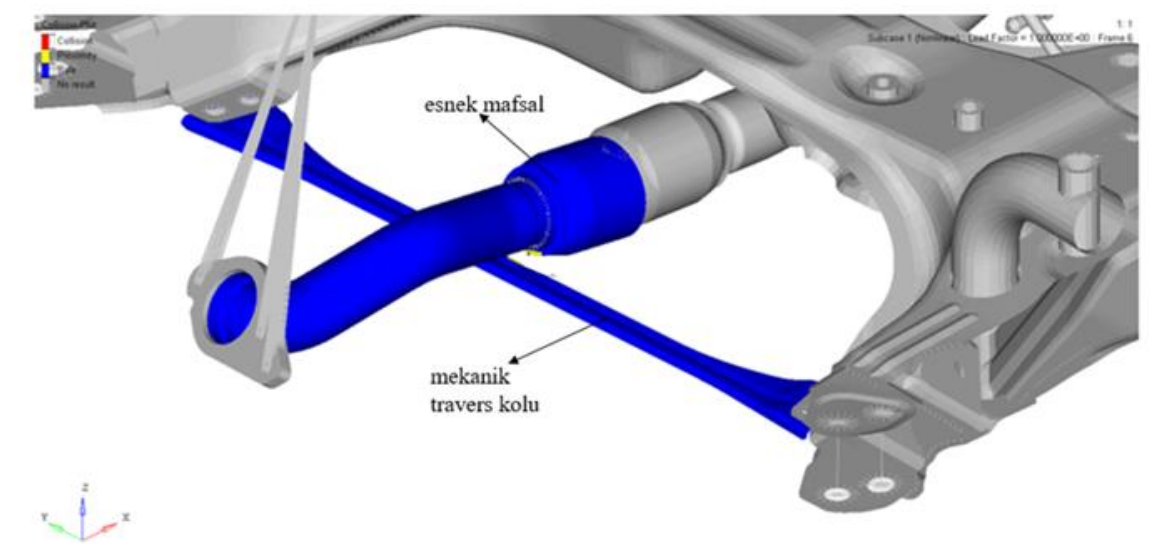

Şekil 7. Esnek mafsal mekanik travers kolu yakınlaşması

\section{Test Koşulları}

Sanal analiz sonrasında elde edilen sonuçların en kritik olanının test ile doğrulanması amacıyla testler gerçekleştirilmiştir. İncelenen konsept mekanik travers kolu ile esnek mafsal arasındaki yakınlık olduğundan, bunun araç seyir halindeyken elde edilebilmesi için, Şekil 8'de görüldüğü gibi mekanik traverse kolu etrafına macun uygulanmıştır. Örülecek macun çapının büyük tutulması, esnek mafsal flanşı tarafindan yakınlaşma sonucu ezilmeyi ölçebilmek için önemlidir. 


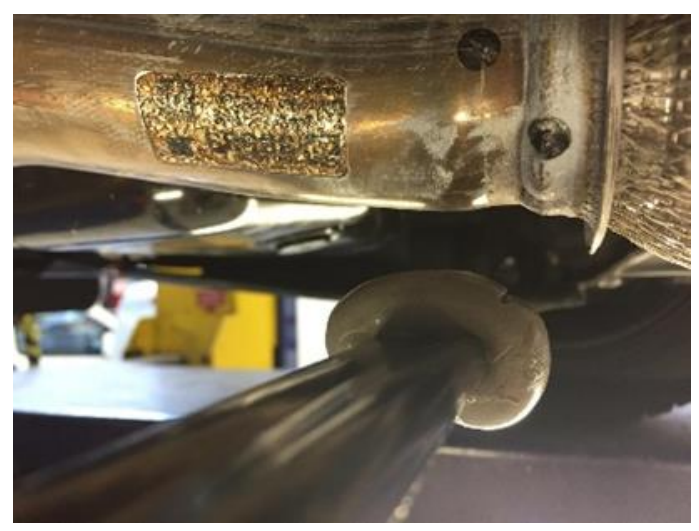

Şekil 8: Mekanik travers kolu üzerine macun uygulaması

Test başlanmadan önce, toleranslar ile araçtan araca farkl1lık gösterebileceğinden, gerçek ölçüyü bilmek adına mekanik travers kolu ile esnek mafsal arasındaki diyagonal mesafe kaydedilmiştir. Operatör aracı durağan halden patinaj sınırıyla kaldırarak ivmeyi çok düşük tutup lifte dönmüştür. Aracın hızlanma ve yavaşlamasında ivmeyi düşük tutmak bu senaryoda önemlidir, aksi takdirde araç ilerleme yönünde senaryoda mevcut olmayan bir ivme yükü oluşturacaktır.

Macun sarma, senaryoyu gerçekleştirme, macun üzerinden ölçüm yapma döngüsü $10 \mathrm{kez}$ tekrar edilmiştir. Sonuçların ortalaması alınarak, kritik senaryo uygulandığında esnek mafsal ile mekanik travers kolu arasındaki yakınlaşma bulunmuştur.

Araç ilerleme doğrultusu ve yer çekimi yönünde diyagonal ölçüm alınıp mesafenin bulunmasının sebebi bu senaryoda egzoz soğuk kısmının herhangi bir yanal yüke maruz kalmamasıdır

\subsection{Test sonuçlart}

Tablo 4'te test sonuçları parametrik olarak gösterilmiştir. Diyagonal yer değiştirme, egzoz soğuk kısmının mekanik travers bölgesinde gerçekleşen araç ilerleme doğrultusu ('x') ve yer çekimi yönündeki (' $z$ ') deplasmanlarıdır. Minimum mesafe ise, mekanik travers kolu ve esnek mafsal flanşı arasında kalan, kapanması halinde temas gerçekleşebilecek olan mesafedir.

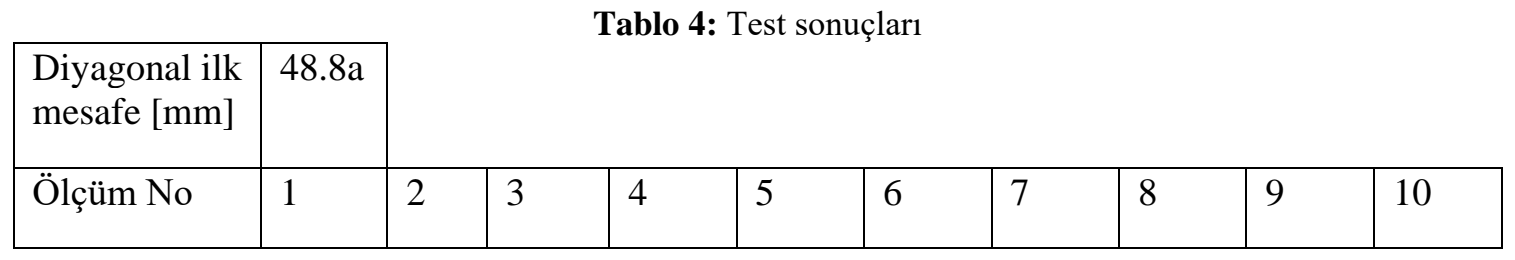




\begin{tabular}{|l|c|l|l|l|l|l|l|l|l|l|}
\hline $\begin{array}{l}\text { Diyagonal } \\
\text { deplasman } \\
\text { [mm }]\end{array}$ & $31.3 \mathrm{a}$ & $\begin{array}{l}31 . \\
5 \mathrm{a}\end{array}$ & $33.1 \mathrm{a}$ & $32.3 \mathrm{a}$ & $32.2 \mathrm{a}$ & $32.1 \mathrm{a}$ & $32.4 \mathrm{a}$ & $32.3 \mathrm{a}$ & $30.9 \mathrm{a}$ & $32.7 \mathrm{a}$ \\
\hline $\begin{array}{l}\text { Minimum } \\
\text { mesafe [mm] }\end{array}$ & $17.5 \mathrm{a}$ & $\begin{array}{l}17 . \\
3 \mathrm{a}\end{array}$ & $15.7 \mathrm{a}$ & $16.5 \mathrm{a}$ & $16.6 \mathrm{a}$ & $16.6 \mathrm{a}$ & $16.4 \mathrm{a}$ & $16.4 \mathrm{a}$ & $17.8 \mathrm{a}$ & $16.0 \mathrm{a}$ \\
\hline
\end{tabular}

\section{Test ile Analiz Sonuçlarının Karşılaştırılması}

Ön analiz ve test sonuçlarının karşılaştırılması parametrik olarak Tablo 5 'te verilmiştir. Test ve analiz başlangıcında, esnek mafsal ile mekanik travers kolu arasındaki mesafe farklı olduğundan, karşılaştırılmalı tabloda egzoz deplasmanı ve yüklerin sonucunda elde edilen yakınlaşma miktarı beraber verilmiştir.

Tablo 5: Test ve analiz sonuçları karşılaştırma

\begin{tabular}{|l|l|l|}
\cline { 2 - 3 } \multicolumn{1}{c|}{} & $\begin{array}{l}\text { Esnek mafsal - mekanik traverse } \\
\text { kolu minimum mesafe }[\mathrm{mm}]\end{array}$ & Egzoz Deplasman1 [mm] \\
\hline Simülasyon & $14.5 \mathrm{a}$ & $37,1 \mathrm{a}$ \\
\hline Test & $16.7 \mathrm{a}$ & $32,1 \mathrm{a}$ \\
\hline Simülasyon ve test fark1 & $\% 13$ & $\% 16$ \\
\hline
\end{tabular}

Sonuçlar arasındaki farklılık, iki sürecin de doğası ve egzoz sistemi modelinin karmaşıklığı düşünüldüğünde fazlasıyla kabul edilebilir olarak değerlendirilmelidir. Sanal analizde en kötü senaryo yaklaşımı ile direngenliği düşük elastik askı modellemesi, egzoz deplasmanlarının nominalden daha fazla olmasını sağlamıştır. Testin operatöre olan bağ lılığı ve macun üzerinden çok hassas ölçüm yapılamaması gibi sonucu bir miktar etkileyecek parametreler de göz ardı edilmemelidir. Güç aktarımı kısmından başlayan toleransların yığılması ve motorun her araçta bir miktar değişkenlik gösterebilecek olan yükleri de sonuçlar arasındaki farklılı̆̆a katkıda bulunmuştur. Son olarak, mekanik travers kolu analizde hareketsiz kabul edilmiştir, gerçekte ise bu parça da bir miktar hareket etmektedir.

\section{Sonuç}

Bu çalışmada egzoz sisteminin sonlu elemanlar modelinin hazırlanması, lineer olmayan yar-statik metodoloji ile belirli yükler altında deplasmanlarının bulunması ve kritik senaryonun test ile doğrulanarak simülasyon ve test arasındaki korelasyonun değerlendirilmesi yapılmıştır.

Araçlarda egzoz sistemi rahatça deplasman yapabilen, esnek olarak araca bağlanan bir sistemdir. Bu sistemin, belirli yükler altında çevre parçalara yakınlaşması, hatta çarpması beklenebilir. Çok 
fazla yakınlaşma ve çarpma istenmediğinden, egzoz sistemi yerleşiminde bu durumlar göz önünde bulundurulmalıdır. Gerçeğe yakın bir sanal analiz modeli oluşturmak yapılacak test miktarını azaltarak hem zamandan kazanılmasına hem de daha fazla miktarda farklı olasılığın değerlendirilebilmesine olanak sağlamaktadır.

$\mathrm{Bu}$ çalışmanın devamında egzoz sisteminin motorun frekansa bağlı tahriklerine göre dinamik yük altında titreşim, yorulma gibi fenomenleri çalışılabilir. Frekansa bağlı elastik askı ve esnek mafsal direngenliği modellenebilir ve rölanti esnasındaki egzoz titreşimleri azaltılabilir

\section{Kaynaklar}

[1] Balaji DJ,Srihari PV, Sheelvanth V.B. Model frequency analysis of automotive exhaust system. International Journal of Mechanical Engineering and Robotics Research 2014; ISSN 2278

[2] Ghasemi A, Dong M, Meda L, Romzek M. CAE dynamic durability simulation of exhaust system. SAE International, 2013; 2031-01-0510, doi: 10.4271/2013-01-0510, USA

[3] Zhien L, Yan Z, Songze D, Shenghao X. Analysis on hanger location and hanger isolator of an exhaust system with powertrain. International Conference on Mechatronics, Electronic, Industrial and Control Engineering; 2014 